\title{
Influence of topography on the endemicity of Kala-azar: a study based on remote sensing and geographical informa- tion system
}

\author{
Gouri S. Bhunia ${ }^{1}$, Shreekant Kesari ${ }^{1}$, Algarsamy Jeyaram², Vijay Kumar ${ }^{1}$, Pradeep Das ${ }^{1}$ \\ ${ }^{1}$ Vector Biology and Control Division, Rajendra Memorial Research Institute of Medical Sciences, \\ Agamkuan, Patna 800 007, Bihar, India; ${ }^{2}$ Regional Remote Sensing Service Centre, ISRO, Kharagpur, West \\ Bengal, India
}

\begin{abstract}
Kala-azar, a fatal infectious disease in many Indian states, particularly in Bihar, West Bengal, Uttar Pradesh, and Jharkhand, is caused by the protozoan parasite Leishmania donovani and transmitted by the sandfly vector Phlebotomus argentipes. The vector is distributed all over the country but the disease is confined to particular zones since before the last century. In this study, parameters such as altitude, temperature, humidity, rainfall and the normalized difference vegetation index (NDVI) were investigated for correlation with the distribution of the disease in the northeastern corner of the Indian sub-continent. Data analysis on Kala-azar prevalence during the period 2005-2007 in the four states showed that the highest prevalence was below $150 \mathrm{~m}$ of altitude with very few cases located above the $300 \mathrm{~m}$ level. Low NDVI value ranges (0.03-0.015) correlated with a high occurrence of the disease. The maximum temperatures in the affected sites varied between an upper level of $25-29^{\circ} \mathrm{C}$ and a minimum of $16-20^{\circ} \mathrm{C}$. The rainfall in these areas fluctuated between 1154 and $1834 \mathrm{~mm}$. As the disease showed a high correlation with the prevailing topographic conditions, an attempt was made to improve the relative strength of the approach to predict the potential for endemicity of leishmaniasis by introducing satellite imagery complemented with a geographical information system database.
\end{abstract}

Keywords: visceral leishmaniasis, Phlebotomus argentipes, topography, normalized differenced vegetation index, geographical information system, remote sensing, India.

\section{Introduction}

Kala-azar, or visceral leishmaniasis (VL), is a deadly disease caused by the parasite protozoa Leishmania donovani and transmitted to humans by the bite of infected female sandflies of the species Phlebotomus argentipes. It is projected that 350 million people in 88 countries are at risk of leishmaniasis and that about 500,000 cases occur annu-

\footnotetext{
Corresponding author:

Pradeep Das

Rajendra Memorial Research Institute of Medical Sciences (ICMR)

Agamkuan, Patna - 800007

Bihar, India

Tel. +91 0612 2631565; Fax +910612 2634379

E-mail: drpradeep.das@gmail.com
}

ally (Indian Council of Medical Research, 2006). The World Health Organization (WHO) estimates that approximately 200 million people are at risk for the disease in South-east Asia and that the number of cases in India, Nepal and Bangladesh amounts to 100,000 (WHO, 2007). About 165 million people are at risk in India, and Bihar state is the worst affected with 31 endemic districts (WHO, 2007). The neighbouring states of West Bengal with 10 districts, Jharkhand with five districts and Uttar Pradesh with four districts are also deemed to be epidemic (Bihar State Health Society, 2007; WHO, 2007).

The distribution of VL is highly influenced by little known geographical and climatic factors that determine the distribution of the sandfly vector, the 
parasites and the animal reservoirs. Tropical climatic conditions favour the transmission of VL which is limited by the presence of suitable breeding places for the $P$. argentipes vector which is therefore rarely found at altitudes exceeding $700 \mathrm{~m}$ above the mean sea level (MSL) (Lysenko, 1971). In India, the largest foci are situated in the north-eastern part of the country, i.e. Bihar, West Bengal, Jharkhand, Uttar Pradesh and some parts of Assam (Fig.1).

Historically, the highlands have been a refuge from the leishmaniasis vector and human infection is uncommon or absent there (Ponirovskii and Charyev, 1996; Sharma et al., 2003; Joshi et al., 2006). Higher altitudes are generally characterized by lower temperatures and a lower relative humidity and these indicators have a tendency of greater fluctuations which affect the distribution of the vec- tor negatively. In the lowlands, on the other hand, humans are especially at risk due to widespread situations suitable for the sandfly vector which prefers a relative humidity of $70-80 \%$ and temperatures between $25^{\circ} \mathrm{C}$ and $28^{\circ} \mathrm{C}$. However, transmission is more focally distributed than in many highland areas since the breeding sites of the vector are concentrated to spatial locations such as river banks, alluvial soil, and dark, damp places such as deep cracks in the soil or rock (Lysenko, 1971; Kalluri et al., 2007; Sharma and Singh, 2008).

Geographical information systems (GIS) can be described as a structure for information-handling with a geographical variable which enables users to process, visualize and analyze data spatially (Clarke et al., 1996; WHO, 1999). In the field of epidemiology, GIS is useful as it seamlessly integrates infor-

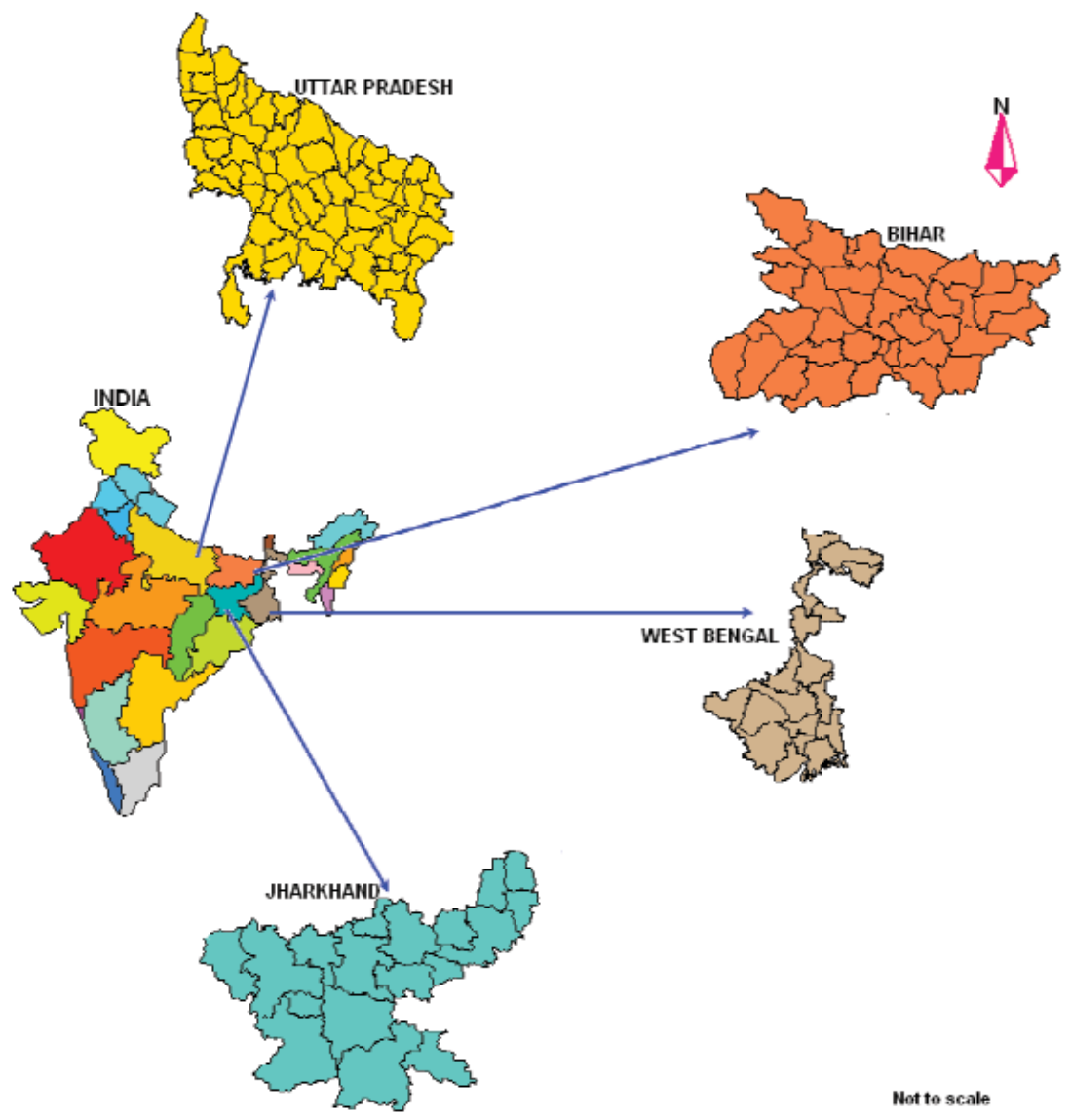

Fig. 1. Map of India showing the states most affected by leishmaniasis. 
mation such as topography, environmental conditions and other particular characteristics. Moreover, this tool allows policy makers to easily visualize problems in relation to existing configurations such as the natural environment, health care and social services, which makes them able to effectively target available resources (WHO, 2005). Another tool is remote sensing (RS) which can be used to locate areas at risk for e.g. Kala-azar by scanning the land cover (Wood et al., 1991; Cross et al., 1996; Miranda et al., 1998; Sithiprasasna et al., 2005; Kalluri et al., 2007). However, it is difficult to map the land cover in mountainous regions using optical imagery because of frequent clouds and the presence of dark shadows. Here we explore an alternative method, i.e. topography modeling using a digital elevation model (DEM), which is a digital representation of the ground topography measuring absolute altitudes above a tidal datum that is defined as the arithmetic mean of hourly water elevations observed over a specific cycle. This approach averages out all tidal highs and lows and defines the MSL reference level as the zero elevation for a local area or the vertical datum (http://www. esri.com/news/arcuser/0703/geoid1of3.html). Based on RS data, these models are constructed as a grid of squares or a raster and have been widely used in the ecologic and environmental sciences for estimating topographic parameters such as elevation, slope, aspect, and ruggedness (Petri and Kennie, 1990). The DEM approach was chosen since it was believed that it would offer a useful base upon which collected data of leishmaniasis risk could be modeled. It was felt that the presentation of the parameters in this way would provide a rapid method for preliminary stratification of the Kalaazar potential in remote highland areas which are difficult to reach and evaluate in any other way.

The overall objective of this study was to investigate topography and vegetation with regard to their suitability for the vectors that transmit Kala-azar on the Indian sub-continent. The study also looks into social status and behaviour of people living in the study area. Climatic information is included as this is of crucial importance for the epidemiology of Kala-azar. A cross-sectional study was carried out and epidemiological data collected to examine how local topography and vegetation densities affect the risk for leishmaniasis. The focus was to identify the areas of Kala-azar in northeastern India and relate this information to the Kala-azar prevalence along an altitude transect. The specific objectives of the study were to:

(i) determine the geographical distribution of Kala-azar in the northeastern part of the Indian sub-continent;

(ii) study the relationship between the incidence of Kala-azar and topography and vegetation density; and

(iii) the socio-economic status of the populations.

\section{Materials and methods}

\section{Study area}

The study focused on Bihar, Jharkhand, West Bengal and Uttar Pradesh making up the major part of the Ganges River plain in north-eastern India (Fig. 1) as these four states bore the brunt of the 20052007 Kala-azar outbreak presenting a large number of cases. The average elevation of Bihar is $53 \mathrm{~m}$ above the India vertical datum MSL (http://www. esri.com/news/arcuser/0703/geoid1of3.html). The corresponding values for Jharkhand and for Uttar Pradesh are $610 \mathrm{~m}$ and $201 \mathrm{~m}$, respectively, while the altitude of West Bengal varies between $73 \mathrm{~m}$ and $293 \mathrm{~m}$. In Bihar, the climate is cool in the winter and hot in the summer and West Bengal is humid and sub-tropical, while Uttar Pradesh and Jharkhand are sub-tropical and dry to semi-humid.

\section{Source of data}

The Kala-azar incidence data were provided by the Rajendra Memorial Research Institute of Medical Sciences (ICMR) in Bihar, India and this information was complemented with satellite and weather data which are provided in Table 1 . 
Table 1. Overview of the data and their sources.

\begin{tabular}{llll}
\hline Data type & Retrieval type & Year & Source \\
\hline Satellite data & SRTM (GTOP30) & 2000 & www.landcover.org \\
& MODIS & 2001 & http://www.tutiempo.net/en/climate \\
Weather data & $\begin{array}{l}\text { From all weather stations } \\
\text { in the study area }\end{array}$ & 2007 & The Rajendra Memorial Research Institute of Medical \\
& $\begin{array}{l}\text { Annual Kala-azar } \\
\text { incidence by district }\end{array}$ & $2005-2007$ & Sciences (ICMR) \\
Census data & & 2001 & Census of India, Census office, Patna, Bihar, India \\
\hline
\end{tabular}

GTOPO30 is a global DEM which has been prepared by approximately $1 \mathrm{~km}^{2}$ tiles covering the full latitudinal extent from $90^{\circ}$ South to $90^{\circ}$ North and the full longitudinal extent from $180^{\circ}$ West to $180^{\circ}$ East (http://www. isprs.org/commission1/ankara06 /makaleler/Yastikli_DEM-Accuracy.pdf).

The satellite data used come from the Moderate Resolution Imaging Spectro-Radiometer (MODIS), derived from the U.S. Geological Service Earth Resources Observation System (EROS) which provides global elevation data. It was felt that this would be a compatible way to independently evaluate the accuracy of DEMs, such as those produced by the Shuttle Radar Topography Mission (SRTM) produced by Jet Propulsion Laboratory, California Institute of Technology, CA, USA (http://www.jpl.nasa.gov/). This mission generated the most complete high-resolution digital topographic database so far based on elevation data collected in February 2000.

All terrestrial data were geo-referenced using the Universal Transverse Mercator (UTM) projection system with the World Geodetic System (WGS)84 datum and North 45 Zone (http://glcfapp.umiacs. umd.edu/data/srtm/description.shtml), based on second order polynomial and the nearest neighbourhood resampling method (Baiocchi and Lelo, 2002; Müller et al., 2002). All the scenes captured were joined as a mosaic and boundary lines of the study areas (the state and district levels) were digitized and the study areas extracted by clipping or sub-setting method using the Earth Resource Data Analysis System (ERDAS) Imagine software, ver- sion 9.2. The DEM was generated with $100 \mathrm{~m}$ exaggeration in virtual GIS viewer and Landsat Thematic Mapper (TM), the multispectral scanning radiometer carried onboard the Landsat satellites 4 and 5. Geo-referenced SRTM elevation data from a $1-\mathrm{km}$ digital elevation model of India were collected from EROS and the data were overlaid throughout the model. Each area was classified into six elevation zones with $50 \mathrm{~m}$ height intervals. The geographical distribution of Kala-azar cases was overlaid on the SRTM ground data (Fig. 2). The vegetation zone map was generated from monthly composite $500 \mathrm{~m}^{2}$ MODIS records. A database was generated on a GIS platform including parameters such as annual maximum, minimum and average temperatures, precipitation and the distribution of the Kala-azar cases. The weather data collected from 100 meteorological stations in India was used to generate a point layer. This database was linked with vector layers and GIS tools used for geo-statistics such as ordinary kriging and spatial interpolation routines, e.g. for transforming point values into interpolated surface. Finally, a thematic map was generated by overlaying all the data layers described above.

Since socio-economic status is also a determinant in the epidemiology of Kala-azar, a socio-behavioural survey was carried out looking at social status parameters such as literacy rate, ethnicity, male/female ratio. It also included economic parameters such as working status and standard of living in each of the districts of the study area affected by Kalaazar. 


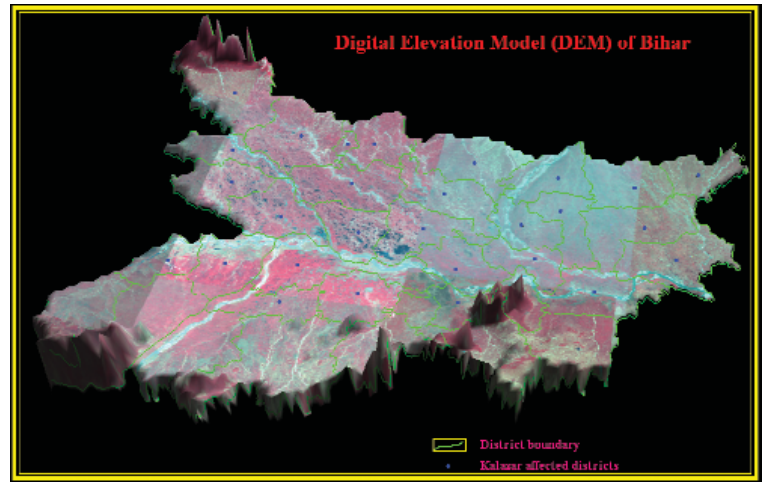

Bihar

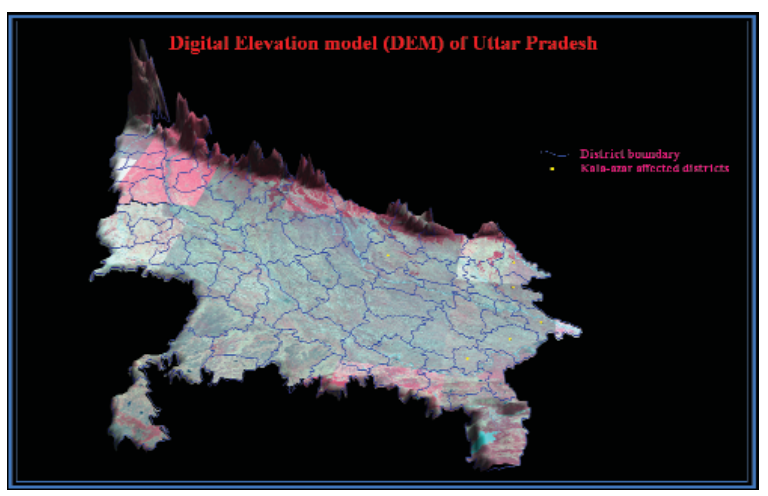

Uttar Pradesh

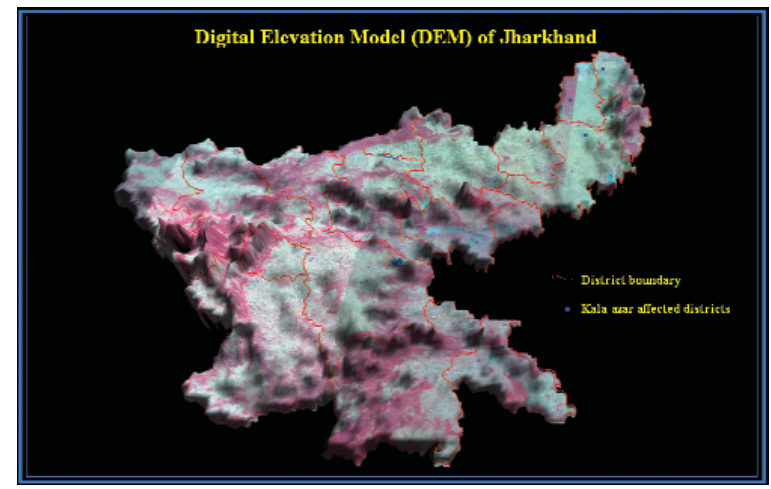

Jharkhand

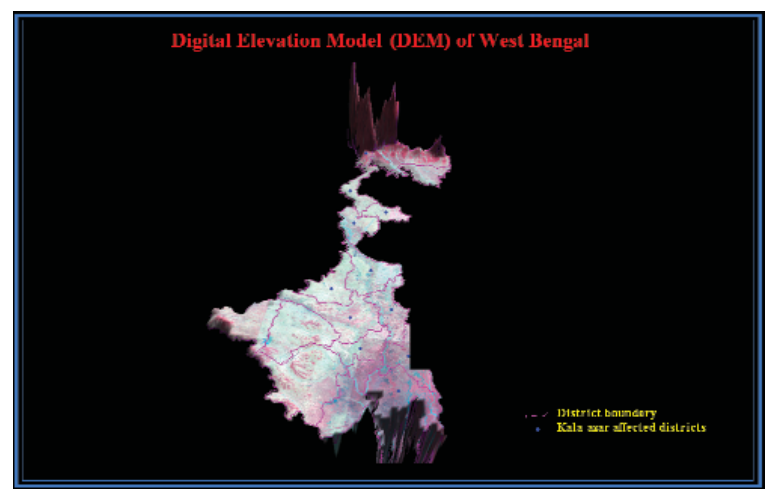

West Bengal

Fig. 2. Relating topography with the distribution of Kala-azar in the study area (computed from SRTM data).

\section{Results}

\section{Topographic analysis}

The topography of the study area was divided into six categories based on altitude, i.e. below $50 \mathrm{~m}, 50$ 99 m, 100-149 m, 150-199 m, 200-249 m, 250-299 $\mathrm{m}$ and above $300 \mathrm{~m}$ (Fig. 2). The number of cases was found to be very high at altitudes below $50 \mathrm{~m}$ to become moderate at the 50-149 m level. At the altitude of $300 \mathrm{~m}$, the number of cases diminished to become eventually nil with increasing height. Figure 2 shows the case distribution by locality using an elevation map as overlay. As can be seen in this figure as well as in Table 2, the distribution of the $P$. argentipes vector is primarily influenced by the altitude and the number of cases decreases progressively with rising altitude.

Table 2. The distribution of Kala-azar cases reported in 2007 at different altitudes.

\begin{tabular}{rrccc}
\hline \multirow{2}{*}{$\begin{array}{c}\text { Altitude } \\
\text { (meters) }\end{array}$} & \multicolumn{4}{c}{ Percent of cases } \\
\cline { 2 - 5 } & Bihar & Jharkhand & West Bengal & Uttar Pradesh \\
\hline$<50$ & 35.2 & 12.9 & 34.1 & 18.3 \\
$50-99$ & 38.9 & 31.7 & 39.9 & 22.3 \\
$100-149$ & 19.5 & 25.7 & 17.1 & 37.1 \\
$150-199$ & 3.8 & 8.2 & 9.0 & 14.9 \\
$200-249$ & 1.6 & 14.3 & - & 7.4 \\
$250-299$ & 1.0 & 7.2 & - & - \\
\hline
\end{tabular}



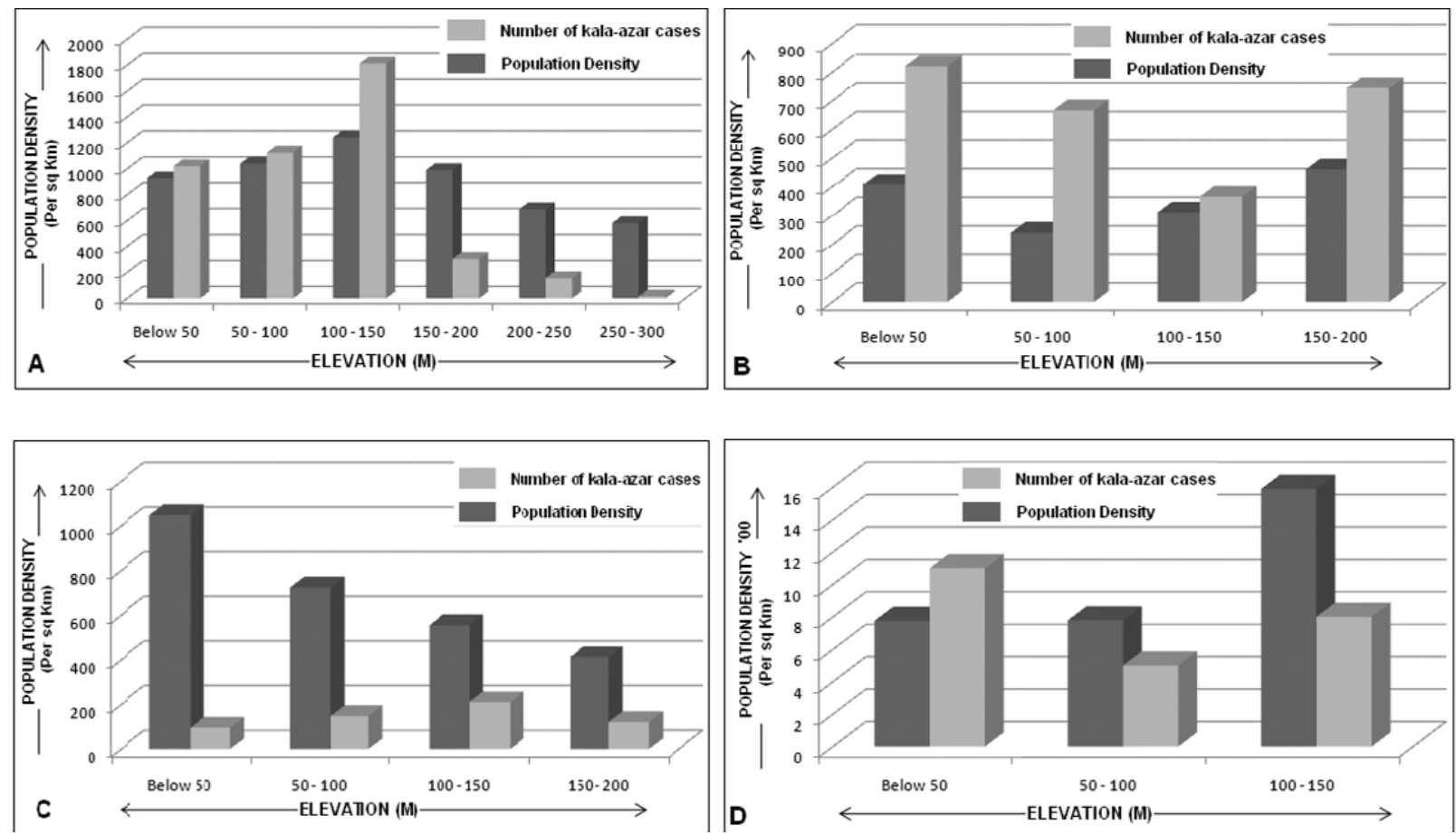

Fig. 3. Relating population density with the distribution of Kala-azar in the study area: Bihar (A), Jharkhand (B), West Bengal (C), Uttar Pradesh (D).

The population density of the study area showed that the density of population and number of cases generally increase up to $150 \mathrm{~m}$ and then gradually declines as shown in Figure 3. However, the trend does not always follow this pattern as seen in Bihar where these parameters are higher at 150-199 m compared to the 100-149 m level. In West Bengal, the population density declines at an almost constant rate, while the number of cases increases except at the 150-199 m level.

\section{Role of meteorological parameters}

Figure 4 represents an overview of the annual mean temperatures, including the maximums and minimums, as well as precipitation in a table of weather data generated for Bihar, Jharkhand, West Bengal and Uttar Pradesh. The data shown were collected from the Indian Meteorological Department.

The overlay of medical data on a map of India indicating prevailing, annual temperatures and pre- cipitation illustrates the significant relationship of leishmaniasis with these parameters (Fig. 5). It is apparent that the annual mean minimum $\left(16-20^{\circ} \mathrm{C}\right)$ and the annual maximum temperatures $\left(25-30^{\circ} \mathrm{C}\right)$, the relative humidity $(80-90 \%)$ and precipitation $(1000-1550 \mathrm{~mm})$ are also significant for producing a suitable environment for the breeding places of the $P$. argentipes vector.

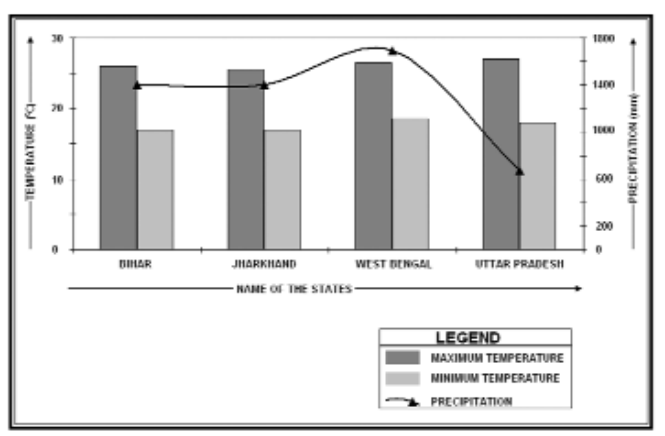

Fig. 4. Average annual maximum and minimum temperature and precipitation in the major Kala-azar-affected states in India. 

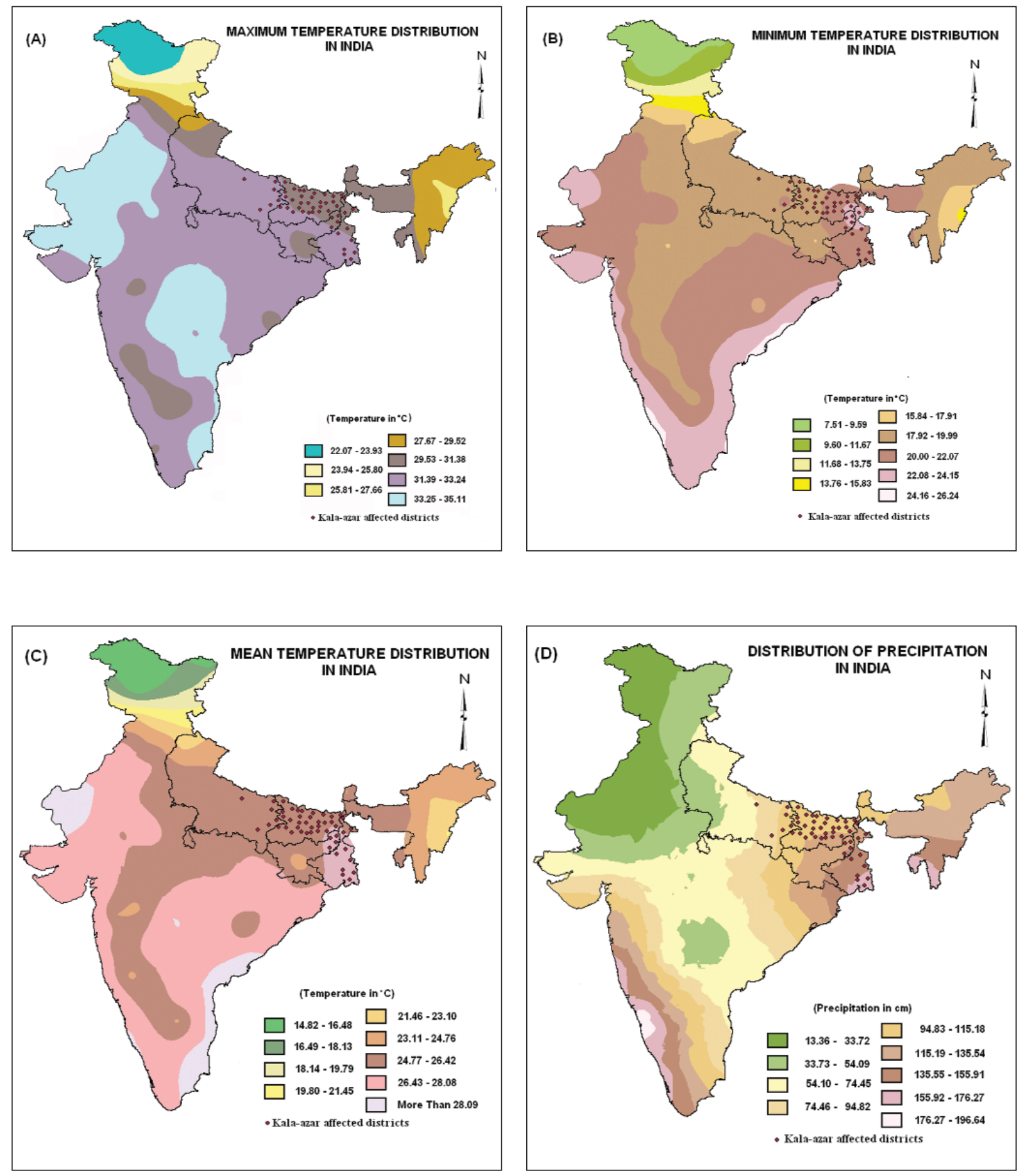

Fig. 5. Weather maps of the India showing the maximum temperature (A), the annual minimum temperature (B), the annual mean temperature (C), and the annual precipitation (D) annotated with the districts stricken by the VL endemic in 2007. 


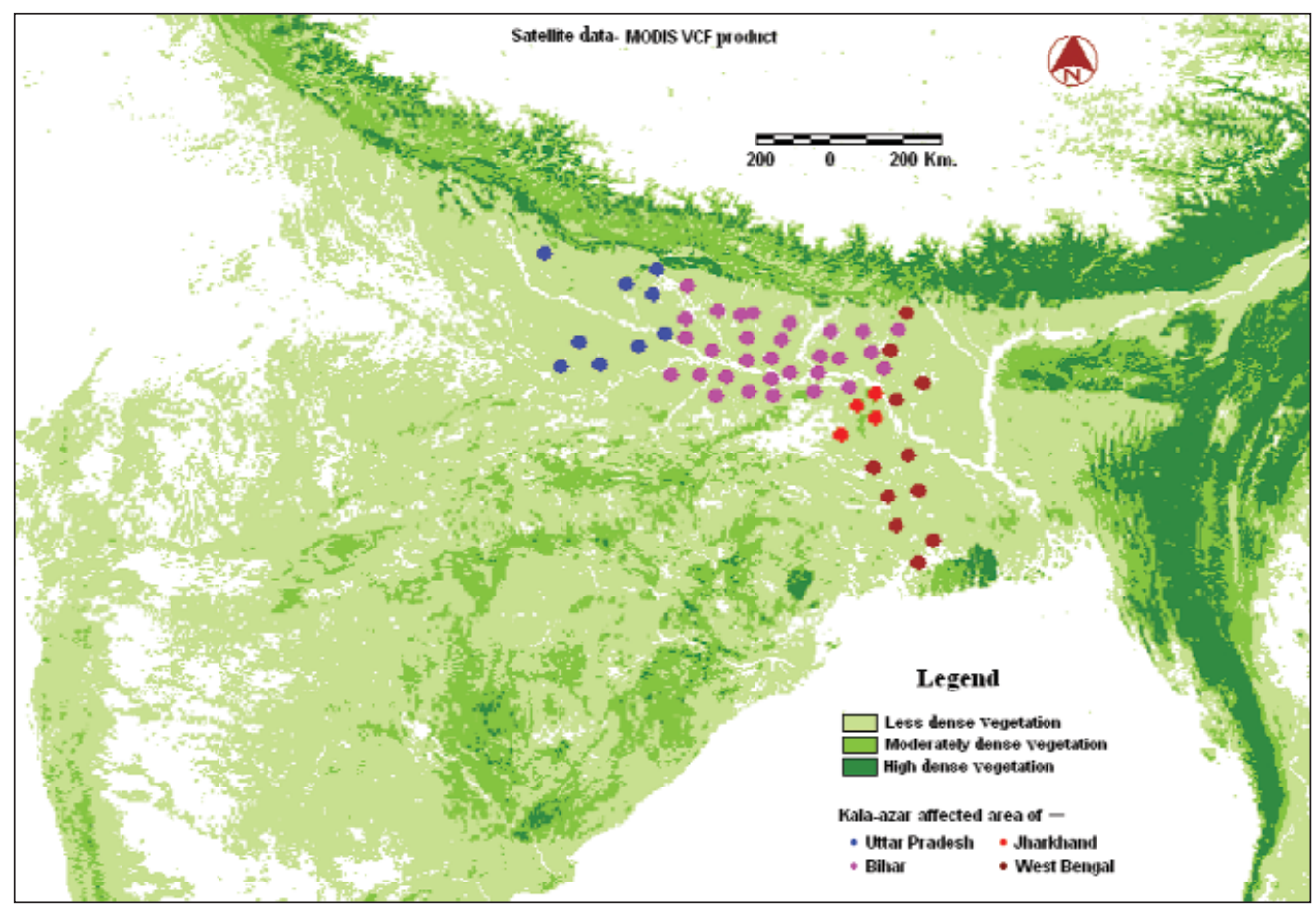

Fig. 6. Relation between vegetation density and Kala-azar incidence in the study area.

\section{NDVI computation}

The NDVI values were computed from MODIS data for Bihar, Jharkhand, West Bengal and Uttar Pradesh. Minimum, maximum, standard deviation and average values of NDVI were computed (Table 3 ) and used to investigate the correlation between Kala-azar positives. Based on NDVI value these data were classified into the vegetation density zone map (Fig. 6) which showed a variety of high density vegetation (0.56-0.48), areas of medium density

Table 3. NDVI in the study area (computed from MODIS data).

\begin{tabular}{lcccc}
\hline State & $\mathrm{NDVI}_{\min }$ & $\mathrm{NDVI}_{\max }$ & $\mathrm{NDVI}_{\text {mean }}$ & $\begin{array}{c}\text { Standard } \\
\text { deviation }\end{array}$ \\
\hline Bihar & -0.55 & 0.81 & 0.11 & 0.39 \\
West Bengal & -0.45 & 0.76 & 0.15 & 0.35 \\
Jharkhand & -0.43 & 0.62 & 0.16 & 0.31 \\
Uttarpradesh & -0.36 & 0.69 & 0.16 & 0.30 \\
\hline
\end{tabular}

(0.34-0.25) and low density zones (0.03-0.015). When we overlaid all reported cases on the NDVI map, the results showed that most of the cases occurred in non-vegetative areas or low-density vegetation zones.

\section{Social status and behaviour}

Table 4 shows the socio-economic status of the populations in each province of India which is affected by Kala-azar. As seen in the table, there is no evidence of a spatial relationship between population density and the number of cases in the district of Jharkhand province, while the three other provinces show positive relations. The study also represents, the male and female ratio among the districts, more or less same. The areas with the highest incidence of Kala-azar were poorer and had a lower literacy rates and economic status. 
Table 4. Social (a), economic (b), and infrastructure (c) indicators in districts of India affected by Kala-azar (source: Census of India, 2001).

Table 4a.

\begin{tabular}{|c|c|c|c|c|c|c|c|c|c|}
\hline \multicolumn{10}{|c|}{ Social parameters } \\
\hline Province & $\begin{array}{l}\text { Number of } \\
\text { districts }\end{array}$ & $\begin{array}{l}\text { Population } \\
\text { density } / \mathrm{km}^{2}\end{array}$ & $\begin{array}{c}\text { Cases } \\
(\%)\end{array}$ & $\begin{array}{l}\text { Male } \\
(\%)\end{array}$ & $\begin{array}{l}\text { Female } \\
(\%)\end{array}$ & $\begin{array}{c}\text { SC* } \\
\text { population }(\%)\end{array}$ & $\begin{array}{c}\text { ST** } \\
\text { population }(\%)\end{array}$ & $\begin{array}{c}\text { Male } \\
\text { literacy }(\%)\end{array}$ & $\begin{array}{c}\text { Female } \\
\text { literacy }(\%)\end{array}$ \\
\hline Bihar & 31 & 960 & 88.5 & 52.4 & 47.6 & 12.0 & 0.7 & 46.3 & 32.0 \\
\hline Jharkhand & 4 & 408 & 7.5 & 51.4 & 48.6 & 5.3 & 34.2 & 40.5 & 21.2 \\
\hline West Bengal & 11 & 1007 & 3.9 & 51.5 & 48.5 & 20.4 & 3.3 & 75.3 & 60.0 \\
\hline Uttar Pradesh & 6 & 762 & 0.1 & 52.4 & 47.6 & 21.8 & 0.1 & 53.0 & 36.9 \\
\hline
\end{tabular}

Table $4 \mathrm{~b}$.

\begin{tabular}{lccc}
\hline \multicolumn{4}{c}{ Economic parameters } \\
\hline Province & $\begin{array}{c}\text { Main workers } \\
(\%)\end{array}$ & $\begin{array}{c}\text { Marginal } \\
\text { workers }(\%)\end{array}$ & $\begin{array}{c}\text { Non-workers } \\
(\%)\end{array}$ \\
\hline Bihar & 24.4 & 11.7 & 64.0 \\
Jharkhand & 25.6 & 16.5 & 57.9 \\
West Bengal & 31.8 & 14.2 & 54.0 \\
Uttar Pradesh & 31.4 & 8.2 & 60.3 \\
\hline
\end{tabular}

\section{Discussion}

As pointed out by Kalluri et al. (2007), the use of RS technology for epidemiological studies gives researchers the opportunity to enhance their understanding of the relationship between vector and environment. We used remotely sensed data to create a quantitatively standardized definition of topographic influence and vegetation density to indicate $P$. argentipes distribution in part of the Indian subcontinent. Our study has provided parameters for the distribution of the Kala-azar vector and the results show significant variation in case diversity within the defined gradient. The conclusion is that the influence of topography (altitude) is of particular importance in predicting disease risk.

It is also obvious from the DEM results (Fig. 2) that the altitude has a relatively strong influence on the distribution of Phlebotomus vector as the Kalaazar incidence is concentrated at low altitudes with
Table 4c.

\begin{tabular}{lccc}
\hline \multicolumn{4}{c}{ Infrastructure } \\
\hline Province & \multicolumn{3}{c}{ Standard of living index $(\%)$} \\
\cline { 2 - 4 } & High & Medium & Low \\
\hline Bihar & 7.7 & 10.7 & 81.6 \\
Jharkhand & 5.3 & 17.5 & 77.2 \\
West Bengal & 5.8 & 20.5 & 73.8 \\
Uttar Pradesh & 5.2 & 15.4 & 80.4 \\
\hline
\end{tabular}

fewer cases in the highlands. The results are in agreement with Hermeto et al. (1994) and Elnaiem et al. (1998) and are also supported by Elnaiem et al. (2003) who investigated the influence of rainfall and altitude on the incidence of Kala-azar in eastern Sudan. The trend observed indicates that a high incidence should be expected at low elevations which was found to be the case. It seems thus clear that altitude is an important environmental factor that must be taken into account when attempting to predict the potential for Kala-azar outbreaks.

The distribution of people and cases in the study area seems to be influenced by altitude, the number of cases progressive decreasing from the lowest level, in which active transmission occurs. Population density appears to be most important factor to the distribution of disease, since its decreasing frequency in samples from increasingly higher altitudes, coincides with the distribution of VL cases. The population density also influenced the 
distribution of cases in the study area, since it occurred in similar numbers at the active and intermediate transmission levels.

Ranjan et al. (2005) investigated ecologic factors favourable for the transmission of Kala-azar in Bihar. The authors considered soil, water table, temperature, annual rainfall, humidity, vegetation and altitude. Combining these data with case data they could show a significant relationship with the meteorological parameters. These analyses showed that the annual mean minimum $\left(16-20^{\circ} \mathrm{C}\right)$ and maximum $\left(25-30^{\circ} \mathrm{C}\right)$ temperature, relative humidity $(80-$ $90 \%)$ and precipitation $(1000-1550 \mathrm{~mm})$ are significant for the spread of $P$. argentipes breeding places (Ranjan et al., 2005).

The NDVI values were computed because the vegetation cover has proved to be a potential tool for monitoring Kala-azar epidemics in tropical countries (Cross et al., 1996). Our results showed that most of the cases occurred in non-vegetative areas or low density vegetation zones which emphasizes that the low density vegetation zones are significant for the $P$. argentipes vector distribution in the affected part of India.

The socio-economic factors for VL, included from the census data 2001, are shown in Table 4. Very little is known about the influence of socio-economic factors on Kala-azar in the disease-endemic areas (Dhiman and Sen, 1991; Dinesh et al., 1994; Thakur, 2000). However, the standard of living index showed that people had very low standards of living in general in those provinces that are highly affected by this disease, reaching above $80 \%$ in Bihar and Uttar Pradesh. It was previously reported that most Kala-azar patients had incomes less than US\$ 1 per day (45 Indian Rupees) (Thakur, 2000). Such poverty may not be a risk factor for Kala-azar, but it can lead to malnutrition, poor housing conditions, lack of preventive measures in the form of illiteracy and low levels of sanitation and economic status. Thus, poverty could be a major determinant for continued transmission of Kala-azar in Bihar and other parts of India.

In conclusion, in the present paper a simple method for defining the distribution of Kala-azar vectors was presented. Moreover, it can also be applied to compare results from previously published studies. The advantage of the approach lies in the easy access to detailed maps over the Internet of many layers, from general geography to environmental information which can be instantly updated as new results appear. The multi-layer cartography approach can play a major role in focusing research and guide control activities. We would be pleased if the approach presented here will inspire further research in this area.

\section{Acknowledgements}

Special thanks to the GLCF community for freely available satellite data supply. This work was carried out with the support of Indian Council of Medical Research (ICMR) task force project.

\section{References}

Baiocchi V, Lelo K, 2002. Confronto di cartografie storiche con cartografie attuali per l'area del centro storico di Roma. Atti della 6a Conferenza nazionale ASITA, Perugina. pp. 243-248.

Bihar State Health Society, 2007. Bihar, India.

Clarke KC, Mclafferty SL, Tempalski BJ, 1996. On epidemiology and geographic information systems. Emerg Infect Dis 2, 85-92.

Cross ER, Newcomb WW, Tucker CJ, 1996. Use of weather data and remote sensing to predict the geographic and seasonal distribution of Phlebotomus papatasi in Southwest Asia. Am J Trop Med Hyg 54, 330-332.

Dinesh DS, Dhiman RC, Ranjan A, Prasad SK, Kishore K, Kar SK, 1994. The cross-sectional epidemiological studies on Kala-azar around Patna City in Bihar. Indian J Parasitol 18, 143-147.

Dhiman RC, Sen AB, 1991. Epidemiology of Kala-azar in rural Bihar (India) using village as a component unit of study. Indian J Med Res 93, 155-160.

Elnaiem DA, Connor SJ, Thomson MC, Hassan MM, Hassan HK, Aboud MA, Ashford RW, 1998. Environmental determinants of the distribution of Phlebotomus orientalis in Sudan. Ann Trop Med Parasitol 92, 877-887.

Elnaiem DE, Schorscher J, Bendall A, Obsomer V, Osman 
ME, Mekkawi AM, Connor SJ, Ashford RW, Thomson MC, 2003. Risk mapping of visceral leishmaniasis: the role of local variation of rainfall and altitude on presence and incidence of Kala azar in eastern Sudan. Am J Trop Med Hyg 68, 10-17.

Hermeto MV, Dias DV, Genaro O, Rotondo-Silva A, Costa CA, Toledo VPCP, Michalick MSM, Williams P, Mayrink W, 1994. Outbreak of cutaneous leishmaniasis in the Rio Doce valley, Minas Gerais, Brazil. Mem Inst Oswaldo Cruz 89, 519-521.

Indian Council of Medical Research, 2006. Research and development for neglected disease. ICMR Bull 36, 6.

Joshi S, Bajracharya BL, Baral MR, 2006. Kala-azar (visceral leishmaniasis) from Khotang. Kathmandu Univ Med J 4, 232-234.

Kalluri S, Gilrut P, Rogers D, Zzczur M, 2007. Surveillence of arthroprod vector borne infectious disease using remote sensing techniques: a review. PLoS Pathog 3, 1361-1371.

Lysenko AJ, 1971. Distribution of leishmaniasis in the old world. Bull World Health Organ 44, 515-520.

Miranda C, Marques CC, Massa JL, 1998. Satellite remote sensing as a tool for the analysis of the occurrence of American cutaneous leishmaniasis in an urban area of Southeastern Brazil. Rev Saude Publica 32, 455-463.

Müller M, Lehner M, Müller R, Reinartz P, Schroeder M, Vollmer B, 2002. A program for direct georeferencing of airborne and spaceborne line scanner images. ISPRS, Commission I, WG I/5. Information available at: http://www.isprs.org/commission1/proceedings $02 /$ paper/00 072.pdf

Petri G, Kennie TJM, 1990. Terrain modeling in surveying and civil engineering. Whittles, London, UK, pp. 1-3.

Ponirovskii EN, Charyev BCh, 1996. The characteristics of the topographical distribution of leishmaniasis in
Turkmenistan. Med Parazitol 1, 13-17.

Ranjan A, Sur D, Singh VP, Siddique NA, Manna B, Lal CS, Sinha PK, Kishore K, Bhattacharya SK, 2005. Risk factors for Indian Kala azar. Am J Trop Med Hyg 73, 74-78.

Sharma RC, Mahajan VK, Sharma NL, Sharma A, 2003. A new focus of cutaneous leishmaniasis in Himachal Pradesh (India). Indian J Dermatol Venereol Leprol 69, 170-172.

Sharma U, Singh S, 2008. Insect vectors of Leishmania: distribution, physiology and their control. J Vector Borne Dis 45, 255-272.

Sithiprasasna R, Lee WJ, Ugsang DM, Linthicum KJ, 2005. Identification and characterization of larval and adult anopheline mosquito habitats in the Republic of Korea: potential use of remotely sensed data to estimate mosquito distributions. Int J Health Geogr 4, 17.

Thakur CP, 2000. Socio-economies of visceral leishmaniasis in Bihar (India). Trans R Soc Trop Med Hyg 94, 156-157.

Wood BL, Beck LR, Washino RK, Palchick SM, Sebesta D, 1991. Spectral and spatial characterization of rice field mosquito habitat. Int J Remote Sens 12, 621-626.

WHO, 1999. Geographical information system (GIS): mapping for epidemiological surveillance. Wkly Epidemiol Rec 74, 281-288.

WHO, 2005. GIS and public health mapping. Information available at: http://www.who.int/health_mapping/gisand$\mathrm{phm} / \mathrm{en} / \mathrm{index} \cdot \mathrm{html}$.

WHO, India, 2007. Information available at: http://www.whoindia.org/Linkfiles/Communicable_ Disease_Kala-Azar_May_07.pdf

WHO, 2007. Guidelines and standard operating procedure for Kala-azar elimination in South-East Asia countries. WHO (Trial Edition) 19 November 2007. Information available at: http://www.searo.who.int/LinkFiles/Kala_azar_VBC85_Rev_1.pdf 